\title{
Functional brain changes associated with cognitive training in healthy older adults: A preliminary ALE meta-analysis
}

\author{
Bryant M. Duda ${ }^{1}$ (D) Lawrence H. Sweet ${ }^{1,2}$ \\ (C) Springer Science+Business Media, LLC, part of Springer Nature 2019
}

\begin{abstract}
Accumulating evidence suggests that cognitive training (CT) programs may provide healthy older adults (OAs) with cognitive benefits that are accompanied by alterations in neural activity. The current review offers the first quantitative synthesis of the available literature on the neural effects of CT in healthy aging. It was hypothesized that OAs would evidence increased and decreased neural activations across various challenging CTs, and that these effects would be observed as significantly altered clusters within regions of the frontoparietal network (FPN). Online databases and reference lists were searched to identify peerreviewed publications that reported assessment of neural changes associated with CT programs in healthy OAs. Among the 2097 candidate studies identified, 14 studies with a total of 238 participants met inclusionary criteria. GingerALE software was used to quantify neural effects in a whole-brain analysis. The activation likelihood estimation technique revealed significant increases in activation following CT in the left hemisphere middle frontal gyrus, precentral gyrus, and posterior parietal cortex, extending to the superior occipital gyrus. Two clusters of diminished neural activity following CT were identified within the right hemisphere middle frontal gyrus and supramarginal gyrus, extending to the superior temporal gyrus. These results provide preliminary evidence of common neural effects of different CT interventions within regions of the FPN. Findings may inform future investigations of neuroplasticity across the lifespan, including clinical applications of CT, such as assessing treatment outcomes.
\end{abstract}

Keywords Cognitive training · Activation likelihood estimation (ALE) · Neuroplasticity $\cdot$ Functional neuroimaging $\cdot$ Healthy aging

\section{Introduction}

The number of individuals aged 65 or older is projected to exceed 1.5 billion in 2050 (National Institute on Aging and World Health Organization 2011) and will comprise approximately 30\% of the population by 2060 (Parker et al. 2012). Advances in healthcare have contributed to a worldwide increase in lifespan; however, this has been accompanied by new challenges to protect the health and safety of older adults

Electronic supplementary material The online version of this article (https://doi.org/10.1007/s11682-019-00080-0) contains supplementary material, which is available to authorized users.

Bryant M. Duda

Bduda@uga.edu

1 Department of Psychology, University of Georgia, Athens, GA 30602-3001, USA

2 Department of Psychiatry \& Human Behavior, Brown University Medical School, Providence, RI, USA
(OAs). It has been estimated that there will be 115 million OAs worldwide living with Alzheimer's disease (AD) by 2050 (Wortmann 2012), which is characterized by a progressive deterioration in cognitive functioning and instrumental activities of daily living (IADL; Alzheimer's Association, 2014; Prince et al. 2013; Roy et al. 2016). These challenges are also experienced by individuals with mild cognitive impairment (Lindbergh et al. 2016) and even extend to healthy OAs, who evidence subtle decrements in cognitive and IADL performance (Schmitter-Edgecombe et al. 2011; Suchy et al. 2011; Duda et al. 2014). Therefore, identification of methods that may attenuate the impact of cognitive and functional decline warrant increased attention.

Normal age-associated changes in cognitive function have been well-documented, including declines in explicit memory (Buckner 2004; Hedden and Gabrieli 2004; Davis et al. 2003), processing speed (Charness 2008; Salthouse 1996), and selective attention (Barr and Giambra 2000; Madden 1990), and these changes contribute to declines in more complex cognitive 
functions, such as working memory (Balota et al. 2000; Zacks et al. 2000) and task-switching (Kray et al. 2002; Kray and Lindenberger 2000). Several studies have also reported on age-related changes in the brain. In structural neuroimaging studies, OAs have exhibited reduced white matter integrity in subcortical prefrontal and parietal regions (Persson et al. 2006; Grady 2012) and gray matter volume within the hippocampus and prefrontal cortices (PFC; Raz et al. 2005; Haug and Eggers 1991). In functional neuroimaging studies, OAs have demonstrated both increases and decreases in brain activity. Decreased brain activity has typically been interpreted as indicative of lower cognitive function and increased activity has been interpreted as "compensatory" when performance levels are maintained (Grady 2012). Compensatory neural changes are the focus of an accumulating body of literature among aging researchers (Elman et al. 2014; Reuter-Lorenz and Park 2014; Morcom and Johnson 2015), as well as other mechanisms that may explain age-related neural changes, including reduced neural efficiency and decreased selectivity of responses, known as dedifferentiation (Grady 2012).

\section{Neuroplasticity across the lifespan}

Theories of age-related efficiency, dedifferentiation, and compensation rest on the assumption that the brain is plastic across the lifespan. Neuroplasticity has been discussed for over a century (Berlucchi and Buchtel 2009), and supported by epidemiological research, which suggests that a lifestyle rich in mental, physical, and social stimulation has beneficial influences on cognition among OAs (Bäckman et al. 2001; Hertzog et al. 2009). The operational definition of neuroplasticity has undergone considerable change over time to include improvements in cognitive performance (Anguera et al. 2013; Mahncke et al. 2006; Ball et al. 2002; Hindin and Zelinski 2012; Colcombe and Kramer 2003), as well as changes in structural (Engvig et al. 2010; Ruscheweyh et al. 2013; Voss et al. 2010; Nagamatsu et al. 2012; May 2011; Nudo 2003) and functional (Voss et al. 2010; Mozolic et al. 2010; Liu-Ambrose et al. 2012; Rosano et al. 2010; Hyodo et al. 2012; see Johansson 2011 for review) neuroimaging indices following cognitive training (CT), exercise, and other rehabilitation interventions in patients affected by brain injury. Converging lines of research thus suggest that the aging brain is also malleable, and such neural markers can be used as valid outcome measures of different types of rehabilitation interventions. Indeed, several efforts have been made to distinguish neural changes associated with different types of CT and exercise programs among OAs (McDaniel et al. 2014; Hindin and Zelinski 2012; Oswald et al. 2006).

\section{Cognitive training}

Cognitive training $(C T)$ has been used to refer to a range of structured programs intended to ameliorate cognitive deficits. As guided practice, standardized CT tasks are intended to challenge particular cognitive functions, including attention, problem solving, and memory (Bahar-Fuchs et al. 2013; Clare and Woods 2004). CT tasks may be presented in paper-and-pencil (Davis et al. 2001; Quayhagen et al. 2000) or computerized form (Kueider et al. 2012; Ball et al. 2002), and may involve hobbies or exemplar activities of daily living (Loewenstein et al. 2004; Neely et al. 2009). Adaptive CT programs, in which task difficulty is adjusted based on individual performance level, are also becoming more available through computerized packages (Peretz et al. 2011). Broadly, CT approaches have been developed based on two primary assumptions: 1) cognitive practice can improve or maintain performance, and 2) significant effects will generalize (i.e., transfer) to tasks within the same domain (Bahar-Fuchs et al. 2013). While support for this second assumption has been mixed in the research literature (Owen et al. 2010; Papp et al. 2009), transfer effects have gained empirical support, and plasticity of anterior executive systems have been suggested as a likely mechanism (Heinzel et al. 2016; Nyberg et al. 2009; Noack et al. 2014; Zinke et al. 2014; Heinzel et al. 2014). Researchers have also broadened the definition of CT to include strategy training, which involves the use of strategies designed to minimize the consequences of $\operatorname{cog}$ nitive impairment while enhancing performance through practice (West et al. 2000; Rebok et al. 2007; Gates and Valenzuela 2010; Gates et al. 2011).

Several meta-analytic studies have provided evidence of age-related behavioral effects of CT. For example, OAs have exhibited significantly improved performance on measures of working memory (WM), processing speed (PS), and other multi-domain cognitive functions, with effects on outcome measures as well as near- and far-transfer effects (Mewborn et al. 2017). In another quantitative review of 52 RCTs and 4885 participants, healthy OAs showed improved verbal and visual memory, WM, PS, and visuospatial skills after CT protocols, which varied across cognitive domains and transfer outcome measures (Lampit et al. 2014). Similarly, data synthesized from 31 RCTs that included 1806 healthy OAs revealed improved performance on measures of WM, PS, and global IQ on trained and transfer tasks (Kelly et al. 2014). In a fourth meta-analysis of 49 RCTs, OAs showed WM and cognitive control gains on trained and near-transfer tasks (Karbach and Verhaeghen 2014).

Individual studies have also produced convincing evidence of CT efficacy in OAs. In the Advanced Cognitive Training for Independent and Vital Elderly trial, 2832 OAs who participated in a 10-session group CT with booster training at 11 months showed improved PS, reasoning, and memory performance on near-transfer tasks for a duration of three years 
(Ball et al. 2002); in addition, a second booster training at 5year follow-up revealed maintenance of cognitive effects for groups that engaged in memory, reasoning, and PS training (Willis et al. 2006). Finally, in a seminal study that used adaptive NeuroRacer CT, healthy OAs showed a trained improvement in multi-tasking skills and transfer effects on measures of sustained attention and WM that persisted for six months. In addition, event-related potential changes were seen within PFC regions (Anguera et al. 2013). Overall, despite variability in study paradigms and effect sizes, this growing literature provides evidence for transfer effects and suggests the efficacy of CT in OAs.

\section{Neurobiological mechanisms of cognitive training}

Neuroimaging is promising as a means of identifying cognitive and neural markers of successful CT. Consistent with evidence that experts tend to have larger brain volumes in regions associated with their type of expertise (Maguire et al. 2003; Gaab et al. 2006), CT has also been associated with regional structural brain changes in OAs. In a study by Engvig et al. (2010) OAs that participated in 8-weeks of memory training demonstrated an improvement in source memory performance that was associated with increases in thickness of the lateral orbitofrontal cortex and fusiform gyrus. In addition, the cognitive effects of video game training have been shown to significantly predict pre-training volume of the dorsal striatum and hippocampus in healthy OAs (Erickson et al. 2010). Finally, global neural effects of CT have also been observed; for instance, OAs have exhibited global increases in gray matter volume following a 3-month protocol that was designed to train participants in three-ball cascade juggling (Boyke et al. 2008).

An increasing number of experiments have used functional neuroimaging to identify biological markers of CT efficacy in OAs, and most have used CT paradigms that were designed to challenge the cognitive functions that are particularly sensitive to aging (e.g., explicit memory, EFs). For example, during an electroencephalography (EEG) investigation of perceptual discrimination CT, OAs revealed transfer benefits extending to a WM task, and these effects were significantly predicted by decreased amplitude of the N1 posterior visual processing region (Berry et al. 2010). OAs have also demonstrated bilateral increases in PFC activity that were associated with performance improvements following longitudinal dual-task training (Erickson et al. 2007). In addition, using localized proton magnetic resonance spectroscopy in three different brain regions, Valenzuela et al. (2003) observed that improved memory performance was associated with increases in neural activity (i.e., concentrations of creatine and choline) of the hippocampus following 5 weeks of memory training. Therefore, CT studies have generally revealed significant but variable neural effects across a variety of CT paradigms and outcome measures.
Several qualitative reviews on this topic have also concluded that CT of healthy OAs is associated with both increases and decreases in task-related neural activity (Bherer 2015; Brehmer et al. 2014; Bamidis et al. 2014; Belleville and Bherer 2012; Lustig et al. 2009). However, due to the nascent nature of the research literature and variable findings, the degree of plasticity in aging and the effects of CT remain largely unknown (Nyberg et al. 2012; Shah et al. 2017). An important challenge for researchers is to understand how extrinsic factors such as CT may modify the neurocognitive consequences of aging. To this end, recent literature reviews have recommended increased use of brain imaging indices to validate the potential utility of CT (Shah et al. 2017; Reuter-Lorenz and Park 2014).

Recent CT investigations using functional neuroimaging have focused greater attention on changes at the network level, and results have largely pointed to the frontoparietal network (FPN), which has been consistently associated with goaldirected cognitive control (Spreng and Schacter 2012). For example, following eight weeks of selective attention training, one study of healthy OAs showed increased resting cerebral blood flow in the right inferior PFC that significantly correlated with reduced interference on a distraction task (Mozolic et al. 2010). In addition, Jolles et al. (2013) reported functional connectivity effects between the right middle frontal gyrus (MFG) and other FPN regions in young adults following six weeks of WM training. Lateralization effects have also been identified, as healthy OAs have shown increased left-lateralization of FPN function following one year of multi-domain CT (Luo et al. 2016). Finally, a recent fMRI meta-analysis of cognitive and motor skills training in young adults also showed altered patterns of neural activity in several nodes of the FPN, including the inferior and posterior parietal cortex, medial and middle PFC, and the middle temporal gyrus (Patel et al. 2013). The consistency of FPN effects across a variety of CT training protocols suggests the presence of common neural mechanism.

A consensus view among researchers maintains that core FPN regions are involved in implementing a wide variety of cognitive tasks (Fox et al. 2005). As a result, a growing theory maintains that the FPN is composed of "flexible hubs," which rapidly shift their engagement to exert cognitive control across a variety of tasks (Cole and Schneider 2007; Zanto and Gazzaley 2013). The "flexible hub" theory builds upon the earlier "guided activation" hypothesis that was used to describe how top-down signals in the lateral PFC and posterior parietal cortex mediate cognitive control functions across varying types of stimuli (Duncan 2010). Consistent with this view, meta-analytic evidence from 193 fMRI studies identified a cognitive control network involving the dorsolateral prefrontal and parietal cortices across a broad range of executive function domains (Niendam et al. 2012). Similarly, using a meta-analytic approach with resting state functional connectivity (FC) studies, Yeo et al. (2014) identified strong correlations among highly flexible frontal and parietal cortices that 
supported multiple and varied tasks. Cole et al. (2013) further tested the "flexible hub" theory using recent advances in neuroimaging methods, including task-state FC, graph theory, and machine learning. This seminal study revealed that, relative to nine other commonly defined networks, the FPN demonstrated the highest brain-wide FC pattern, which shifted across 64 practiced and novel tasks. Pertinent to the current study, the "flexible hub" theory suggests that the FPN may be particularly malleable following a wide variety of CT paradigms.

Evidence of age-related reductions in FPN function (see Goh 2011 for review) suggest that hubs of the FPN are sensitive to aging (i.e., dorsolateral PFC, inferior PFC, and inferior parietal cortex) and have been inversely associated with taskswitching performance (Gold et al. 2010). Similarly, relative to their younger counterparts, healthy OAs have shown reduced FC of the FPN that significantly correlated with verbal task-switching performance (Madden et al. 2010). In addition, other cognitive processes may also be affected by age-related alterations of the FPN; for example, healthy OAs have exhibited differences in neural activation within dorsal prefrontal and parietal cortices, relative to younger adults, which correlated with WM performance (Nyberg et al. 2009). Moreover, age and hypertension have been associated with reduced taskrelated activity of FPN during numerous cognitive tasks (Campbell et al. 2012; Heinzel et al. 2015), while increased activity in the FPN appear to act as a compensatory neural mechanism (Heinzel et al. 2015). Overall, these findings indicate that the FPN may be sensitive to the consequences of aging, as well as positive effects of CT, which suggest that the network is characterized by high plasticity.

Recent neuroimaging studies of CT effects have largely pointed to the FPN as a primary mechanism of adaptive change (Spreng and Schacter 2012). The "flexible hub" theory, which posits that the FPN is both highly flexible and engaged by a wide variety of challenges (e.g., stimuli non-specific, novel and practiced tasks), further corroborates this view and offers a theoretical basis for the consistency of recent CT findings (Cole et al. 2013). Moreover, a recent fMRI meta-analysis of cognitive and motor skills training in young adults found that CT effects were associated with altered patterns of neural activity within primary regions of the FPN (Patel et al. 2013). Behavioral evidence of CT efficacy has further substantiated these findings, as several meta-analytic studies have reported age-related CT effects, including near- and fartransfer effects, across variable study designs and outcome measures (Mewborn et al. 2017; Lampit et al. 2014; Kelly et al. 2014; Karbach and Verhaeghen 2014). Given the evidence of a "flexible" FPN that is sensitive to the aging process (Goh 2011) and has demonstrated adaptive change following a variety of CT paradigms, an fMRI metaanalysis of CT effects in OAs may be expected to produce CT effects that are associated with the FPN.
The present meta-analytic review offers a preliminary quantitative synthesis of the literature in order to investigate the presence of core neural effects within regions of the FPN that have been associated with CT programs among healthy OAs. We expected to find regional effects related to $\mathrm{CT}$ efficacy that were not bound by a particular training approach. Consistent with the weight of the available literature and the recent trend in identification of common neural effects within the FPN utilizing fMRI paradigms, it was hypothesized that OAs would (1) demonstrate both changes in neural activity relative to pre- and post-CT scans (i.e., increases and decreases in neural activity), with (2) expected changes in PFC and parietal regions that contribute to the frontoparietal "cognitive control" network.

\section{Method}

The present meta-analytic review was conducted in accordance with Preferred Reporting Items for Systematic Reviews and Meta-Analyses (PRISMA) statement guidelines (Moher et al. 2009) with modifications due to methodological differences between behavioral meta-analysis and activation likelihood estimation (ALE), such as the use of statistical probability maps weighted by number of foci and sample size rather than effect sizes.

\section{Article selection}

Candidate articles published by March 1st, 2018, were identified using the PubMed/MEDLINE, and PsychINFO online databases using a specific keyword search string:

(“2018/03/01”[Publication Date]) AND (older adults OR elderly) AND (cognitive training OR cognitive intervention OR strategy training OR process training OR multimodal training) AND (fMRI OR functional MRI OR functional magnetic resonance imaging OR PET OR positron emission tomography). Reference lists of relevant articles were manually searched for additional publications not captured in the online database searches.

The criteria for inclusion were: (1) peer-reviewed publication; (2) available in the English language; (3) use of healthy older adult human subjects with a sample size of at least five; (4) reported use of a neurocognitive assessment to screen for impairment; (5) full text available; (5) use of a cognitive training program; (6) within-group study design or use of a matched-control group; (7) pre- and post-CT neuroimaging assessment of task-related brain activity acquired via fMRI or PET, (8) whole-brain analyses with reported Montreal Neurologic Institute (MNI) or Talairach coordinates. Articles were excluded if analyses were limited to a special elderly 
population (e.g., mild cognitive impairment or dementia), or conducted relative to a non-matched control group (e.g., younger adults, individuals with mild cognitive impairment or dementia). Other exclusion criteria included studies with insufficient data available to include in ALE analysis following attempts to contact corresponding authors. A flow chart illustration of the literature review and study selection process can be viewed in Fig. 1.

\section{Contrast selection}

All contrasts reflected statistically significant whole brain clusters active during a post-training cognitive task (i.e., time point 2) relative to a pre-training cognitive task (i.e., time point 1; see Table 1). In studies that reported significant clusters of activity from more than one outcome measure, only foci from the primary measure were included in the meta-analysis (i.e., the same paradigm used pre-training or a near-transfer task). Two ALE contrasts were performed as part of the present ALE analysis. Contrast 1 represented increases in brain activity following $\mathrm{CT}$, assessed post-training relative to pretraining. Contrast 2 represented decreases in brain activity following $\mathrm{CT}$, assessed pre-training relative to posttraining. Each outcome measure is labeled by cognitive domain in Table 1.

\section{Activation likelihood estimation (ALE) procedure}

Activation likelihood estimation (Laird et al. 2005; Turkeltaub et al. 2002) is a coordinate-based quantitative meta-analysis method that has been used to identify consistent locations of brain activation elicited across studies employing similar experimental conditions or tasks. In ALE, activation foci are reported in published studies and treated as probability distributions centered at the reported coordinates. Activation probabilities are then calculated for each standard-space voxel to construct ALE maps for contrasts of interest. To determine the reliability of the ALE map, null-distributions are generated by analyzing the distribution of ALE values across independent studies, which is conceptually similar to using permutation tests of individual voxels across experiments; the contribution of each study is weighted by its sample size, and each study is treated as a random effect (Eickhoff et al. 2009). The observed values in the ALE distribution are then compared to the null distribution in order to assign probability estimates to the observed experimental data (Eickhoff et al. 2012). The present study used GingerALE v2.3 (http://www.brainmap.org) with a conservative mask size and a variable FWHM spatial filter kernel (Eickhoff et al. 2009) with the application of a streamlined permutation test and improved statistical corrections (Eickhoff et al. 2012). A cluster-based multiple comparisons correction was used in which an uncorrected threshold of $p<$. 01 was permuted 100 times to arrive at a minimum cluster volume that guarantees a $p<.005$ probability of a false positive. All ALE coordinate clusters are reported in MNI space. A detailed description of the ALE process and analysis procedures can be found on the Brainmap website (http://www. brainmap.org/ale/manual.pdf).
Fig. 1 Flowchart of the literature search and study selection process, based on PRISMA template (Moher et al. 2009)

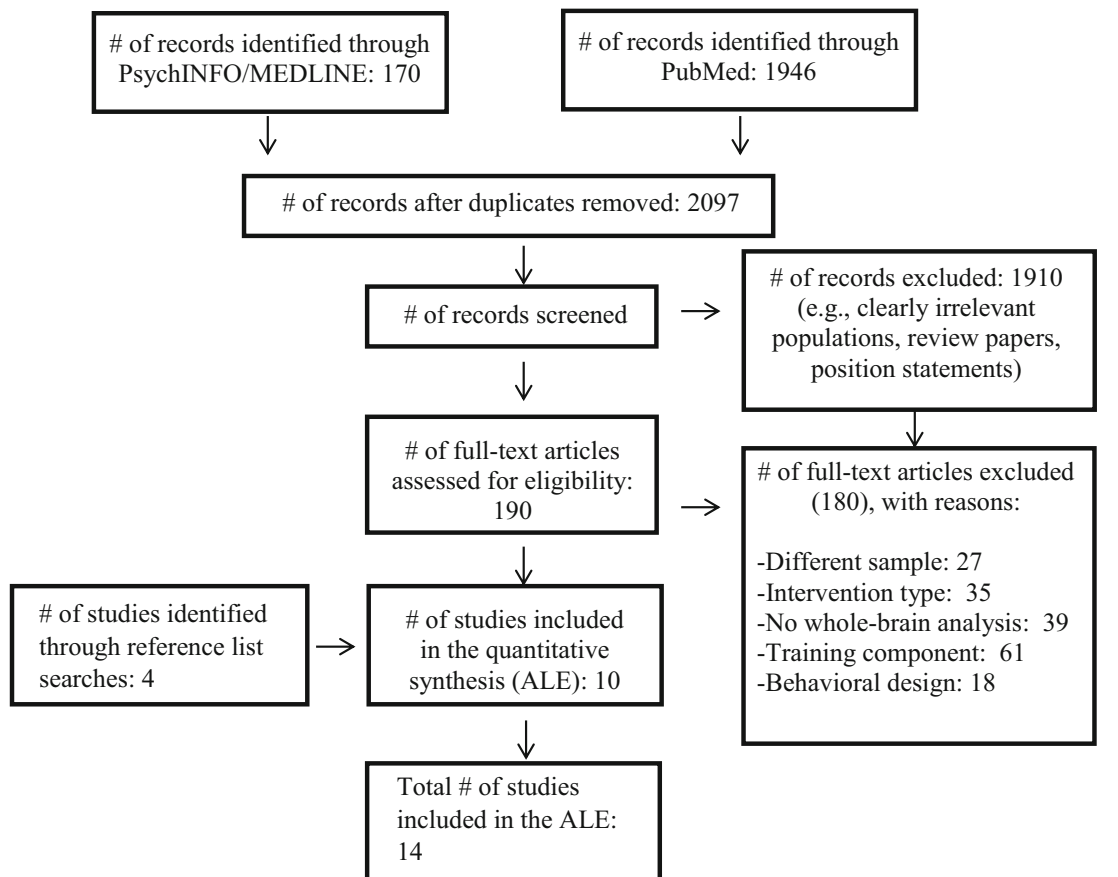


Table 1 Characteristics of studies included in the meta-analysis

\begin{tabular}{|c|c|c|c|c|c|c|c|c|}
\hline Year & 1st author & Canna st(s) & Training Type & Training Protocol & Duration & fMRI task & $\mathrm{N}$ & Control \\
\hline 2003 & Nyberg & Post $>$ Pre & Strategv & Episodic Memory & 1 day & Episodic Memory & 16 & + \\
\hline 2008 & Dahlin & Both & State gy/Process & Working Memory & $11.25 \mathrm{~h} / 5 \mathrm{wks}$ & Letter Memory & 11 & + \\
\hline 2009 & Braver & Post $>$ Pre & Strategy & Cognitive $\mathrm{C}$ ontrol & 1 day & Cognitive Control & 16 & - \\
\hline 2011 & Belleville & Both & Strategy & Episodic Memory & $12 \mathrm{~h} / 6 \mathrm{wks}$ & Episode Memory & 15 & - \\
\hline 2011 & Brehmer & Pre $>$ Post & Stategy/Process & Working Memory & $10.5 \mathrm{~h} / 5 \mathrm{wks}$ & Working Memory & 12 & + \\
\hline 2011 & Kirchoff & Both & Strategy & Semantic Encoding & 1 day & Semantic Encoding & 16 & - \\
\hline 2012 & Osaka & Post $>$ Pre & Stategy/Process & Attention & 1 day & Working Memory & 23 & + \\
\hline 2014 & Belleville & Both & Strategy & Divided Attention & $6 \mathrm{~h} / 2 \mathrm{wks}$ & Divided Attention & 14 & - \\
\hline 2015 & Balardin & Both & Strategy & Episodic Memory & 1 day & Episodic Memory & 17 & + \\
\hline 2015 & McDonough & Post $>$ Pre & Multimodal & Group Activities & $210 \mathrm{~h} / 14 \mathrm{wks}$ & Semantic Classification & 23 & + \\
\hline 2016 & Heinzel & Pre $>$ Post & Stategy/Process & Working Memory & $9 \mathrm{~h} / 4 \mathrm{wks}$ & Working Memory & 16 & - \\
\hline 2017 & Chapman & Post $>$ Pre & Strategy & Multidomain & $36 \mathrm{~h} / 12 \mathrm{wks}$ & Reasoning/Flexitility & 15 & + \\
\hline 2017 & Murphy & Post $>$ Pre & Strategy/Process & Mental Imagery & $12 \mathrm{~h} / 4 \mathrm{wks}$ & Reasoning/Imagery & 32 & + \\
\hline 2018 & Motes & Pre $>$ Post & Strategy & Multidomain & $12 \mathrm{~h} / 12 \mathrm{wks}$ & Processing Speed & 12 & + \\
\hline
\end{tabular}

\section{Results}

\section{Article inclusion}

The final analyses included 14 task-based fMRI experiments that included 238 OAs. Across the study pool, twelve contrasts yielded coordinates in which study OAs exhibited increased brain activation following a CT program, and eight studies $(N=113)$ yielded coordinates in which OAs exhibited decreases in brain activation following a CT program. With respect to length of training protocols, five studies employed shortduration (i.e., 1 day) CTs while nine studies utilized longduration CTs (i.e., 2-14 weeks). Two of the included studies used some component of adaptive training (e.g., difficulty increased when a participant's accuracy $>80 \%$ ). Results of the two ALE contrasts did not indicate overlap between the post-training $>$ pre-training and pre-training $>$ post-training contrast maps (i.e., they were spatially discrete). The total number of foci entered into the ALE analysis was 117, including 68 foci representing clusters of post-training increases in brain activation, and 49 foci representing clusters of post-training decreases in brain activation. The neuroanatomical region names for each resulting cluster were derived from the output of the ALE software.

\section{Increased activation}

OAs exhibited increased activation relative to pre-training in three regions, (1) the left middle frontal gyrus (weighted center, MNI: $\mathrm{x}=-37, \mathrm{y}=0, \mathrm{z}=55)$ and a large cluster comprised of several distinct regions in (2) the left posterior parietal cortex (weighted center, MNI: $\mathrm{x}=-32, \mathrm{y}=-76, \mathrm{z}=39$ ) with extrema values extending to the left superior occipital gyrus (peak, MNI: $\mathrm{x}=-40, \mathrm{y}=78, \mathrm{z}=30$ ), and (3) the left precentral gyrus (peak, MNI: $x=-41, y=4, z=31$ ). An ALE cluster map of activation increases observed at post-training is shown in Fig. 2, with red clusters representing significant increases in activation following CT. Coordinates and volumes of increased activation clusters can be found in Table 2 .

\section{Diminished activation}

OAs exhibited diminished activation relative to pre-training in two regions, (1) the right middle frontal gyrus (weighted center, MNI: $x=34, y=15, z=37$ ) and (2) the right supramarginal gyrus of the parietal lobe (weighted center, MNI: $x=52, y=$ $-50, z=31$ ) with extrema values extending to the right superior temporal gyrus (peak, MNI: $x=50, y=-48, z=24$ ). An ALE cluster map of activation decreases (blue clusters) observed at post-training is shown in Fig. 2. Coordinates and volumes of diminished activation clusters can be found in Tables 3 and 4 .

\section{Behavioral performance}

Across the 14 studies included in the analyses, 20 measures of pre- and post- cognitive performance accuracy were collected and subsequently converted to a uniform metric (i.e., Cohen's d). Consistent with qualitative and quantitative reviews of behavioral effects related to $\mathrm{CT}$ in aging (Silsupadol et al. 2009; Karbach and Verhaeghen 2014), the effect sizes of these cognitive improvements were variable (range $=0.21-4.39$ ), though also large in scale (mean $=1.41 ; \mathrm{SD}=1.05$ ).

\section{Discussion}

The primary aim of the present ALE meta-analysis was to offer the first quantitative summary of the available literature on core neural regions that are associated with $\mathrm{CT}$ approaches 
Fig. 2 Clusters of significant neural change following cognitive training. Notes: Images shown in left $=$ left orientation. Cluster centers of mass are reported in Tables 2 and 3 in RAI oriented MNI coordinates. Axial view, zplane coordinates listed

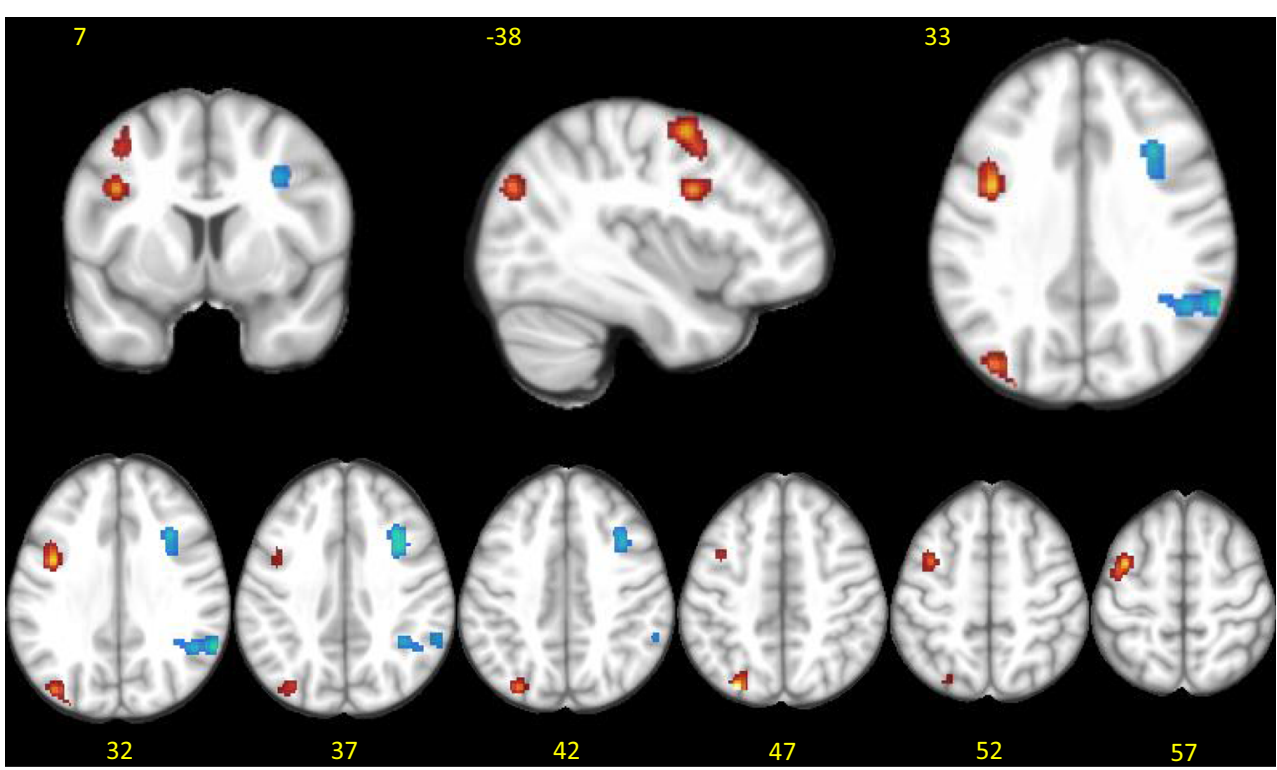

in healthy aging. It was first determined whether reliable increases and decreases in neural activity were evident following CT, and if clusters of significant effect were located within regions of the FPN. As hypothesized, OAs demonstrated significant increases and decreases in neural activity following CT; however, findings revealed mixed support regarding the location of these neural effects. As hypothesized, three clusters of significant change were located within the FPN (i.e., left MFG, right MFG, and left posterior parietal cortex). A large cluster centered in the left posterior parietal cortex extended into the superior occipital gyrus, and a fifth cluster was identified within the right supramarginal gyrus that extended into the STG. Overall, these findings suggest that OAs demonstrate common neural effects associated with different CTs within the FPN and extending into adjacent regions. All experiments in the ALE reported improvements on the target or a near-transfer task, indicating that the observed neural changes were associated with effective CT.

The largest cluster of increased activation was located within the left posterior parietal cortex, a region with high connectivity to the PFC and the rest of the cerebral cortex (Fair et al. 2007; Vincent et al. 2008). The posterior parietal cortex has been associated with a range of highly integrated tasks,

Table 2 ALE clusters derived from Post-training > Pre-training contrasts

\begin{tabular}{lllll}
\hline Structure & Volume $(\mathrm{mm} 3)$ & $\mathrm{x}$ & $\mathrm{y}$ & $\mathrm{z}$ \\
\hline $\begin{array}{l}\text { L Posterior Parietal/Superior } \\
\text { occipital gyrus }\end{array}$ & 2600 & -32 & -76 & 39 \\
L Middle frontal gyrus & 1904 & -37 & 0 & 55 \\
L Precentral gyrus & 1448 & -41 & 4 & 31 \\
\hline
\end{tabular}

L, Left; Coordinates reported in center of mass MNI coordinates, RAI orientation. These clusters are shown in red in Fig. 2 including task-switching (Sohn et al. 2000), explicit memory retrieval (Hutchinson et al. 2009), spatial awareness (Karnath et al. 2001), planning and control of visually guided movements (Buneo and Andersen 2006), and both top-down (Ciaramelli et al. 2008) and bottom-up attentional control (Buschman and Miller 2007).

Significant clusters of both increased and diminished activation were identified within the left and right MFG, respectively. The MFG has been found to support several EFs, including WM (Rypma et al. 1999) and cognitive control (Kerns et al. 2004), and has been associated with a variety of agerelated brain changes and associated reductions on cognitive tasks. For example, age-related reductions in MFG volume has been associated with both compensatory PFC activity and episodic retrieval difficulties. In addition, several studies have reported a relation between reduced MFG activity and decreased information processing speed (Ranganath and Rainer 2003; Solbakk et al. 2008). CT-related changes in neural activity of the MFG have also been reported following several CTs. For example, Li et al. (2014) reported an agerelated reduction in $\mathrm{FC}$ of the MFG following a 6-week multimodal intervention. In addition, following 5-6 weeks of WM raining, younger adults have shown increased MFG activity that was significantly correlated with WM performance

Table 3 ALE clusters derived from Pre-training > Post-training contrasts

\begin{tabular}{lllll}
\hline Structure & Volume $(\mathrm{mm} 3)$ & $\mathrm{x}$ & $\mathrm{y}$ & $\mathrm{z}$ \\
\hline $\begin{array}{l}\text { R Supramarginal/ Superior } \\
\text { temporal gyrus }\end{array}$ & 3384 & 52 & -50 & 31 \\
R Middle frontal gyrus & 2488 & 34 & 15 & 37 \\
\hline
\end{tabular}

R, Right; Coordinates reported in center of mass MNI coordinates, RAI orientation. These clusters are shown in blue in Fig. 2 
Table 4 Behavioral effect sizes of studies that contributed to significant ALE Clusters

\begin{tabular}{llll}
\hline $\begin{array}{c}\text { Activation increases } \\
\text { Right middle frontal gyrus }\end{array}$ & $n$ & Foci & Cohen's $d$ \\
Brehmer (2011) & 12 & 1 & 1.27 \\
Belleville (2014) & 14 & 1 & 1.32 \\
Heinzel (2016) & 16 & 1 & 1.99 \\
Belleville (2011) & 15 & 1 & 0.26 \\
Right supramarginal gyrus & & & \\
Heinzel (2016) & 16 & 3 & 1.99 \\
Belleville (2011) & 15 & 1 & 0.26 \\
Balardin (2015) & 17 & 2 & 0.59 \\
& & & \\
Activation Decreases & & & \\
Left middle frontal gyrus & & & 1.16 \\
Nyberg (2003) & 16 & 1 & 0.59 \\
Balardin (2015) & 17 & 1 & 0.21 \\
Kirchoff (2011) & 16 & 1 & 0.84 \\
Braver (2009) & 16 & 1 & 0.59 \\
Left posterior parietal cortex & & & 1.16 \\
Balardin (2015) & 17 & 1 & \\
Nyberg (2003) & 16 & 4 & \\
Left precentral gyrus & & 1 & \\
Kirchoff (2011) & 16 & 2 & \\
Balardin (2015) & 17 & & \\
\hline
\end{tabular}

${ }^{a}$ Studies that reported effect sizes on two different measures of cognitive performance; these effects were converted to a common metric (Cohen's d) and averaged across measures

(Jolles et al. 2013; Olesen et al. 2004). Heinzel et al. (2016) reported a decreased MFG response that was associated with improvement on WM and transfer EF tasks following a 12week Sternberg training. Finally, Yin et al. (2014) reported increased MFG activity that positively correlated with psychomotor speed and set-shifting following a 6-week multimodal training. Evidence thus suggests that neural effects may be prominent in the MFG following CT and warrant future investigation.

A cluster of increased activation was centered in the left precentral gyrus. The precentral gyrus has been wellestablished as the site of the primary motor cortex. Several studies have identified age-related alterations in the precentral gyrus, such as cortical thinning (Salat et al. 2004), that was predictive of later cognitive impairment (Pacheco et al. 2015) and increased functional activation relative to younger counterparts during the Stroop task (Langenecker et al. 2004). Pertinent to the current study, evidence suggests that the precentral gyrus supports a wide range of FPN functions (Braunlich et al. 2015). For example, among OAs, a semantic encoding-strategy training has been shown to result in increased brain activity in the precentral gyrus that corresponded with cognitive improvements. The precentral gyrus has also been identified as a contributor to the FPN (Braunlich et al.
2015) and among OAs, a region that is susceptible to change following semantic encoding strategy training (Bier et al. 2017; Li et al. 2016) and physical exercise interventions (Wood et al. 2016; Chirles et al. 2017; Ruffieux et al. 2018).

The second cluster of diminished activation post-CT was centered in the right supramarginal gyrus, an association region of the parietal cortex that is primarily engaged in language processing in the left hemisphere (Price 2010). However, the right supramarginal gyrus has also been found to engage during phonological decision-making (Hartwigsen et al. 2010), verbal working memory (Deschamps et al. 2014), and verbal creativity processes (Fink et al. 2015). The supramarginal gyrus also appears to be affected by the normal aging process, including volumetric atrophy (Fjell et al. 2009), and decreased functional connectivity with regions of the posterior cingulate, right middle, and inferior frontal cortices (Wu et al. 2011). One interpretation of the observed post-CT decrease within the supramarginal gyrus is related to the nature of the tasks being trained. The vast majority of CT protocols in the present ALE employed EF tasks using verbal stimuli, suggesting that effects in the supramarginal gyrus might reflect a potential mechanism to offset natural, age-related brain changes in EF.

The adjacent STG has been well-established as a region associated with memory functioning, with several studies reporting structural and functional correlates of reduced memory function among OAs (Smith et al. 2016; Geerligs et al. 2014; Abutalebi et al. 2014). Evidence indicates that the STG is also a region that contributes to the DMN (Mason et al. 2007; Uddin et al. 2009), and suggests age-related changes in DMN suppression required for task-positive network functioning (Persson et al. 2007; Tomasi et al. 2006; Anticevic et al. 2010). Similar to the neural effects observed in the supramarginal gyrus, alterations within the STG seen among healthy OAs may reflect a more task-specific compensatory process. The significant cluster of decreased neural activation identified within the right supramarginal gyrus and STG may be differentially engaged according to task demands, such as greater language or memory demands. This finding is supported by some healthy OA-specific CT literature, including observations of increases and decreases in hippocampal activity associated with improved verbal recall following five weeks of memory training (Valenzuela et al. 2003), and decreased amplitude of posterior $\mathrm{N} 1$, a posterior processing network with a node identified in the supramarginal gyrus, following perceptual discrimination training (Berry et al. 2010). Berry et al. (2010) also identified improvement on a far-transfer WM task, indicating that neural effects in sensory processing regions may benefit higher-order cognitive processing in healthy aging.

The cluster identified in the left posterior parietal cortex that extended into the left superior occipital gyrus is consistent with visual association processes responsible for binding simple and complex properties of information such as orientation, spatial frequency, and color (von der Heydt et al. 1984; Qiu 
and Von Der Heydt 2005). Increased activation of the superior occipital gyrus following CT may reflect an increase in the allocation of resources to this region to account for age-related reductions in sensory processing and their influence on cognitive functions ( $\mathrm{Li}$ and Lindenberger 2002). There is also evidence to suggest that the superior occipital gyrus may also play an important role in visual memory processing (Bussey and Saksida 2007), including more challenging match-tosample WM tasks (Nagahama et al. 1996, 1999).

In addition to the primary findings, results of the present ALE meta-analysis yielded notable trends. For example, length of training appears to affect neural correlates of CT. All four studies contributing to clusters of increased activation involved short-term CT (i.e., 1 day), while two of the three studies that contributed to clusters of diminished activation involved CT that was longer in duration (i.e., $9 \mathrm{~h} / 6$ weeks, $6 \mathrm{~h} / 2$ weeks). Post-hoc ALE analyses confirmed this trend, with studies contributing to clusters of increased and decreased neural response specific to short- and long-term CT, respectively (see Supplementary materials). Activation increases have been thought to represent increased or redistributed neural response following practice of sensory or motor tasks (Buschkuehl et al. 2012), while decreases have been commonly attributed to increased neural efficiency via training (Kelly et al. 2006). Prior studies of the neural effects associated with CT duration have produced mixed results. Consistent with the present findings, FPN activations associated with improved cognitive performance have been seen following long-term CT in both OAs (Jolles and Crone 2012; Erickson et al. 2007) and younger adults (Schneiders et al. 2011); however, several studies of younger adults have shown the opposite pattern. For example, long-term CT has been associated with activation increases (Hempel et al. 2004; Dux et al. 2009), and short-term CT (i.e., 1 day, < 4 h) has produced activation decreases in FPN regions (Garavan et al. 2000; Sayala et al. 2006). Overall, there appears to be a link between CT duration that may be influenced by participants' age.

Post-CT changes differed by hemisphere; increases were seen in the left hemisphere, with decreases observed in the right hemisphere. Several potential explanations of this finding warrant further investigation. First, several studies point to a reduced FPN response to repeated stimulus exposure (Ranganath and Rainer 2003; Olesen et al. 2004) that may be more right-lateralized (Yamaguchi et al. 2004; Kirino et al. 2000) and sensitive to aging (Solbakk et al. 2008). Second, Erickson et al. (2007) observed a reduction in hemispheric asymmetry among OAs following a longitudinal dualtask CT that was driven by activation decreases observed in FPN regions. This finding was interpreted in the context of a prominent compensatory model of aging, the hemispheric reduction asymmetry in OAs (HAROLD), which posits that task-related PFC activation tends to be less lateralized in OAs (Cabeza 2002). This pattern has been illustrated in simple motor (Mattay et al. 2002) as well as more complex verbal WM and explicit retrieval tasks (Bäckman et al. 1997; Reuter-Lorenz et al. 2000). The ALE-derived clusters of reduced asymmetry observed in the present study may therefore reflect a reduced need for a HAROLD process that supported successful task completion prior to CT. The three lefthemisphere clusters of increased activation observed in the present ALE may reflect a separate neurocompensatory effect; for example, age-related increases in neural activations have been thought to reflect differences in "capacity," or the degree to which a brain network is maximally recruited to perform a task (Barulli and Stern 2013). This process has also been associated with maintenance of cognitive functioning (Bosch et al. 2010), and relative to the current study, suggests that CT-induced increases in activation may counter reduced neural functioning and associated cognitive decline in OAs.

\section{Limitations}

The present study has several limitations that are common to efforts to synthesize neuroimaging literature. First, while the number of studies in the present ALE were comparable to other oft-cited fMRI meta-analyses (Nee et al. 2014; Outhred et al. 2013; Brown et al. 2005; Wegbreit et al. 2014), it may have limited our power to detect effects.

Several steps were taken to address this potential issue. To address the challenges of study heterogeneity and the ALE method (Costafreda 2009), we used a deliberately exhaustive literature search with relatively strict inclusion criteria (e.g., exclusion of ROI-limited studies, non-healthy OAs) and a rigorous correction procedure (e.g., conservative FDR and cluster size thresholds) intended to increase the internal validity of the study in accord with prior ALE studies (Frank et al. 2014; Filkowski et al. 2017; Sabatinelli et al. 2011). The study is therefore intended to serve as a preliminary investigation of the most robust functional brain changes associated with $\mathrm{CT}$ in OAs, with findings discussed in the context of current models of agerelated neurocompensation and reported changes in functional connectivity studies of CT.

Several measures were taken to limit study heterogeneity using fMRI meta-analysis (Costafreda 2009). These include limiting study inclusion to coordinates from within-group whole-brain voxelwise fMRI analyses of non-demented OAs as determined via screening measures. Trends observed within the primary findings were also tested for validity using additional ALE analyses (i.e., short- vs. long-duration CT) which revealed results consistent with the primary findings. Although study heterogeneity is inevitable in pooling CT studies (Reuter-Lorenz and Park 2014; Nyberg et al. 2012), we believe that the observed neural effects that generalize across studies, such as our FPN findings across CT types, are meaningful. It has been pointed out that this use of ALE has been 
may be more likely to be linked to a substantive research question under consideration than to unique study designs (Costafreda 2009).

Other general limitations with respect to ALE should also be noted. ALE is a coordinate-based meta-analytic method in which each study is summarized by a set of locations of peak activation. As a result, all relevant hemodynamic information or detailed methodology of any given experiment cannot be fully considered despite the chosen conservative thresholds. For example, ALE does not use effect sizes to weigh the unique contribution of each study as some behavioral metaanalytic techniques do. This study includes use of improvements to the ALE algorithm that were intended to address this weakness, including weighing the contribution of each study by its sample size and treating each study as a random effect (Eickhoff et al. 2009, 2012). Relatedly, the coordinate-based method does not allow for a quantitative assessment of publication bias or study quality. Considerable effort was made to address this issue by searching for unpublished studies or data not reported by the authors of relevant studies (see Fig. 1). Lastly, the ALE algorithm only calculates main effects. However, as demonstrated by the present study, trends can be identified and tested for validity via additional analyses (see Supplementary materials).

\section{Conclusions and future directions}

Meta-analytic evidence of positive cognitive performance outcomes (Mewborn et al. 2017; Lampit et al. 2014; Kelly et al. 2014; Karbach and Verhaeghen 2014), and several qualitative reviews that have evaluated the neural effects associated with CTs (Bamidis et al. 2014; Bherer 2015; Lustig et al. 2009; Belleville and Bherer 2012), suggest that reliable neural effects may be associated with CT in healthy OAs. However, the complexity of CTs and heterogeneity within the available literature base pose a challenge for researchers interested in understanding the neural mechanisms associated with reported improvements in cognition. The present study offered the first quantitative synthesis of the literature to investigate common neural effects associated with CTs among healthy OAs. Findings from the ALE indicate that common neural effects may be associated with CT in the FPN that support cognitive control processes, including the posterior parietal cortex and MFG. However, significant changes in neural activity were also identified in the superior occipital gyrus, supramarginal gyrus, and MTG, suggesting that these effects may mediate cognitive improvements in several ways. For example, altered activity within the superior occipital gyrus may reflect changes in sensory processing that in turn benefit higher order cognitive processes. In addition, the location and direction of observed neural changes following CT may be influenced by several factors, such as the type and duration of training (i.e., cognitive domain, outcome measure). This latter theory is consistent with the INTERACTIVE model which suggests that training-induced brain activity changes may depend on numerous interacting factors, including the format and characteristics of training (Belleville et al. 2014).

Future studies of CT-related neural effects may benefit from increased attention to several factors highlighted by prior literature and the present findings. First, general methodological factors, such as the use of an RCT study design and consistency among the samples studied, offer means to address potential confounds such as CT-related practice effects or general age differences in neural functioning. Second, researchers may wish to consider measuring neural effects of $\mathrm{CT}$ at multiple time points to more precisely identify the neural mechanisms of CT. Within the motor training field, for example, Doyon and colleagues (Doyon et al. 2003; Doyon and Benali 2005) have offered a theoretical framework to describe a well-studied pattern of neural changes that occur at different phases of motor skills training. For example, in this model, the authors suggest that experience-dependent changes in the brain depend on both the stage of learning, as well as a requirement to learn a new skill (e.g., sequence of movement). Finally, as the literature base continues to grow, researchers can begin to quantitatively synthesize data with respect to the type of training, outcome measures used, age of participants, and length of training. This may shed light upon the neural mechanisms through which brain health can be improved or maintained in the face of adverse changing in aging.

\section{Compliance with ethical standards}

Disclosures The authors had no conflict of interest when conducting this research or reporting the results.

Informed consent Authors of the studies selected for the present ALE meta-analysis indicated that all procedures were conducted in accordance with the ethical standards of the responsible committee on human experimentation (institutional and national) and with the Helsinski declaration of 1975, and the applicable revisions at the time of each investigation. Informed consent was obtained from all participants included in each study

\section{References}

Abutalebi, J., Canini, M., Della Rosa, P. A., Sheung, L. P., Green, D. W., \& Weekes, B. S. (2014). Bilingualism protects anterior temporal lobe integrity in aging. Neurobiology of Aging, 35(9), 2126-2133.

Alzheimer's Association. (2014). Alzheimer's disease facts and figures. Alzheimer's \& Dementia, 10(2), e47-e92.

Anguera, J. A., Boccanfuso, J., Rintoul, J. L., Al-Hashimi, O., Faraji, F., Janowich, J., et al. (2013). Video game training enhances cognitive control in older adults. Nature, 501(7465), 97-101.

Anticevic, A., Repovs, G., Shulman, G. L., \& Barch, D. M. (2010). When less is more: TPJ and default network deactivation during encoding predicts working memory performance. NeuroImage, 49(3), 26382648. 
Bäckman, L., Almkvist, O., Andersson, J., Nordberg, A., Windblad, B., Rineck, R., et al. (1997). Brain activation in young and older adults during implicit and explicit retrieval. Journal of Cognitive Neuroscience, 9, 378-391.

Bäckman, L., Small, B. J., \& Wahlin, A. (2001). Aging and memory. Handbook of the Psychology of Aging, 349-377.

Bahar-Fuchs, A., Clare, L., \& Woods, B. (2013). Cognitive training and cognitive rehabilitation for mild to moderate Alzheimer's disease and vascular dementia. The Cochrane Library.

Balardin, J. B., Batistuzzo, M., Moraes Martin, M. D. G., Sato, J., Smid, J., Porto, C., et al. (2015). Differences in prefrontal cortex activation and deactivation during strategic episodic verbal memory encoding in mild cognitive impairment. Frontiers in Aging Neuroscience, 7 , 147

Ball, K., Berch, D. B., Helmers, K. F., Jobe, J. B., Leveck, M. D., Marsiske, M., et al. (2002). Effects of cognitive training interventions with older adults: A randomized controlled trial. JAMA, 288(18), 2271-2281.

Balota, D. A., Dolan, P. O., \& Duchek, J. M. (2000). Memory changes in healthy older adults. The Oxford Handbook of Memory, 395-409.

Bamidis, P. D., Vivas, A. B., Styliadis, C., Frantzidis, C., Klados, M., Schlee, W., Siountas, A., \& Papageorgiou, S. G. (2014). A review of physical and cognitive interventions in aging. Neuroscience \& Biobehavioral Reviews, 44, 206-220.

Barr, R., \& Giambra, L. (2000). Age-related decrement in auditory selective attention. Psychology of Aging, 5(4), 597-599.

Barulli, D., \& Stern, Y. (2013). Efficiency, capacity, compensation, maintenance, plasticity: Emerging concepts in cognitive reserve. Trends in Cognitive Sciences, 17(10), 502-509.

Belleville, S., \& Bherer, L. (2012). Biomarkers of cognitive training effects in aging. Current Translational Geriatrics and Experimental Gerontology Reports, 1(2), 104-110.

Belleville, S., Clement, F., Mellah, S., Gilbert, B., Fontaine, F., \& Gauthier, S. (2011). Training-related brain plasticity in subjects at risk of developing Alzheimer's disease. Brain, 134(6), 1623-1634.

Belleville, S., Mellah, S., de Boysson, C., Demonet, J. F., \& Bier, B. (2014). The pattern and loci of training-induced brain changes in healthy older adults are predicted by the nature of the intervention. PLoS One, 9(8), e102710.

Berlucchi, G., \& Buchtel, H. A. (2009). Neuronal plasticity: Historical roots and evolution of meaning. Experimental Brain Research, 192(3), 307-319.

Berry, A. S., Zanto, T. P., Clapp, W. C., Hardy, J. L., Delahunt, P. B., Mahncke, H. W., \& Gazzaley, A. (2010). The influence of perceptual training on working memory in older adults. PLoS One, 5(7), e11537.

Bherer, L. (2015). Cognitive plasticity in older adults: Effects of cognitive training and physical exercise. Annals of the New York Academy of Sciences, 1337(1), 1-6.

Bier, B., Mellah, S., \& Belleville, S. (2017). Timecourse of brain and cognitive changes following two types of attentional training programs: A three-time points fMRI intervention study in older adults. Alzheimer's \& Dementia: The Journal of the Alzheimer's Association, 13(7), P893.

Bosch, B., Bartrés-Faz, D., Rami, L., Arenaza-Urquijo, E. M., FernándezEspejo, D., Junqué, C., et al. (2010). Cognitive reserve modulates task-induced activations and deactivations in healthy elders, amnestic mild cognitive impairment and mild Alzheimer's disease. Cortex, 46(4), 451-461.

Boyke, J., Driemeyer, J., Gaser, C., Büchel, C., \& May, A. (2008). Training-induced brain structure changes in the elderly. Journal of Neuroscience, 28(28), 7031-7035.

Braunlich, K., Gomez-Lavin, J., \& Seger, C. A. (2015). Frontoparietal networks involved in categorization and item working memory. NeuroImage, 107, 146-162.
Brehmer, Y., Rieckmann, A., Bellander, M., Westerberg, H., Fischer, H., \& Bäckman, L. (2011). Neural correlates of training-related working-memory gains in old age. Neuroimage, 58(4), 1110-1120.

Brehmer, Y., Kalpouzos, G., Wenger, E., \& Lövdén, M. (2014). Plasticity of brain and cognition in older adults. Psychological Research, 78(6), 790-802.

Braver, T. S., Paxton, J. L., Locke, H. S., \& Barch, D. M. (2009). Flexible neural mechanisms of cognitive control within human prefrontal cortex. Proceedings of the National Academy of Sciences, 106(18), 7351-7356.

Brown, S., Ingham, R. J., Ingham, J. C., Laird, A. R., \& Fox, P. T. (2005). Stuttered and fluent speech production: An ALE meta-analysis of functional neuroimaging studies. Human Brain Mapping, 25(1), $105-117$

Buckner, R. L. (2004). Memory and executive function in aging and AD: Multiple factors that cause decline and reserve factors that compensate. Neuron, 44, 195-208.

Buneo, C. A., \& Andersen, R. A. (2006). The posterior parietal cortex: Sensorimotor interface for the planning and online control of visually guided movements. Neuropsychologia, 44(13), 2594-2606.

Buschkuehl, M., Jaeggi, S. M., \& Jonides, J. (2012). Neuronal effects following working memory training. Developmental Cognitive Neuroscience, 2, S167-S179.

Buschman, T. J., \& Miller, E. K. (2007). Top-down versus bottom-up control of attention in the prefrontal and posterior parietal cortices. Science, 315(5820), 1860-1862.

Bussey, T. J., \& Saksida, L. M. (2007). Memory, perception, and the ventral visual-perirhinal-hippocampal stream: Thinking outside of the boxes. Hippocampus, 17(9), 898-908.

Cabeza, R. (2002). Hemispheric asymmetry reduction in older adults: The HAROLD model. Psychology and Aging, 17(1), 85-100.

Campbell, K. L., Grady, C. L., Ng, C., \& Hasher, L. (2012). Age differences in the frontoparietal cognitive control network: Implications for distractibility. Neuropsychologia, 50(9), 2212-2223.

Chapman, S. B., Spence, J. S., Aslan, S., \& Keebler, M. W. (2017). Enhancing innovation and underlying neural mechanisms via cognitive training in healthy older adults. Frontiers in Aging Neuroscience, 9, 314.

Charness, N. (2008). Aging and human performance. Human Factors, $50,548-555$.

Chirles, T. J., Reiter, K., Weiss, L. R., Alfini, A. J., Nielson, K. A., \& Smith, J. C. (2017). Exercise training and functional connectivity changes in mild cognitive impairment and healthy elders. Journal of Alzheimer's Disease, 57(3), 845-856.

Ciaramelli, E., Grady, C. L., \& Moscovitch, M. (2008). Top-down and bottom-up attention to memory: A hypothesis (AtoM) on the role of the posterior parietal cortex in memory retrieval. Neuropsychologia, 46(7), 1828-1851.

Clare, L., \& Woods, R. T. (2004). Cognitive training and cognitive rehabilitation for people with early-stage Alzheimer's disease: A review. Neuropsychological Rehabilitation, 14(4), 385-401.

Colcombe, S., \& Kramer, A. F. (2003). Fitness effects on the cognitive function of older adults: A meta-analytic study. Psychological Science, 14(2), 125-130.

Cole, M. W., \& Schneider, W. (2007). The cognitive control network: Integrated cortical regions with dissociable functions. NeuroImage, 37(1), 343-360.

Cole, M. W., Reynolds, J. R., Power, J. D., Repovs, G., Anticevic, A., \& Braver, T. S. (2013). Multi-task connectivity reveals flexible hubs for adaptive task control. Nature Neuroscience, 16(9), 1348-1355.

Costafreda, S. G. (2009). Pooling fMRI data: Meta-analysis, megaanalysis and multi-center studies. Frontiers in Neuroinformatics, 3, 33.

Dahlin, E., Nyberg, L., Bäckman, L., \& Neely, A. S. (2008). Plasticity of executive functioning in young and older adults: Immediate training 
gains, transfer, and long-term maintenance. Psychology and Aging, 23(4), 720-730.

Davis, R. N., Massman, P. J., \& Doody, R. S. (2001). Cognitive intervention in Alzheimer disease: A randomized placebo-controlled study. Alzheimer Disease \& Associated Disorders, 15(1), 1-9.

Davis, H. P., Small, S. A., Stern, Y., Mayeux, R., Feldstein, S. N., \& Keller, F. R. (2003). Acquisition, recall, and forgetting of verbal information in long-term memory by young, middle-aged, and elderly individuals. Cortex, 39(4), 1063-1091.

Deschamps, I., Baum, S. R., \& Gracco, V. L. (2014). On the role of the supramarginal gyrus in phonological processing and verbal working memory: Evidence from rTMS studies. Neuropsychologia, 53, 39 46.

Doyon, J., \& Benali, H. (2005). Reorganization and plasticity in the adult brain during learning of motor skills. Current Opinion in Neurobiology, 15(2), 161-167.

Doyon, J., Penhune, V., \& Ungerleider, L. G. (2003). Distinct contribution of the cortico-striatal and cortico-cerebellar systems to motor skill learning. Neuropsychologia, 41(3), 252-262.

Duda, B., Puente, A. N., \& Miller, L. S. (2014). Cognitive reserve moderates relation between global cognition and functional status in older adults. Journal of Clinical and Experimental Neuropsychology, 36(4), 368-378.

Duncan, J. (2010). The multiple-demand (MD) system of the primate brain: Mental programs for intelligent behaviour. Trends in Cognitive Sciences, 14(4), 172-179.

Dux, P. E., Tombu, M. N., Harrison, S., Rogers, B. P., Tong, F., \& Marois, R. (2009). Training improves multitasking performance by increasing the speed of information processing in human prefrontal cortex. Neuron, 63(1), 127-138.

Eickhoff, S. B., Laird, A. R., Grefkes, C., Wang, L. E., Zilles, K., \& Fox, P. T. (2009). Coordinate-based activation likelihood estimation meta-analysis of neuroimaging data: A random-effects approach based on empirical estimates of spatial uncertainty. Human Brain Mapping, 30(9), 2907-2926.

Eickhoff, S. B., Bzdok, D., Laird, A. R., Kurth, F., \& Fox, P. T. (2012). Activation likelihood estimation meta-analysis revisited. NeuroImage, 59(3), 2349-2361.

Elman, J. A., Oh, H., Madison, C. M., Baker, S. L., Vogel, J. W., Marks, S. M., et al. (2014). Neural compensation in older people with brain amyloid-[beta] deposition. Nature Neuroscience, 17(10), 13161318.

Engvig, A., Fjell, A. M., Westlye, L. T., Moberget, T., Sundseth, Ø., Larsen, V. A., \& Walhovd, K. B. (2010). Effects of memory training on cortical thickness in the elderly. Neuroimage, 52(4), 1667-1676.

Erickson, K. I., Colcombe, S. J., Wadhwa, R., Bherer, L., Peterson, M. S., Scalf, P. E., et al. (2007). Training-induced plasticity in older adults: Effects of training on hemispheric asymmetry. Neurobiology of Aging, 28(2), 272-283.

Erickson, K. I., Boot, W. R., Basak, C., Neider, M. B., Prakash, R. S., Voss, M. W., et al. (2010). Striatal volume predicts level of video game skill acquisition. Cerebral Cortex, 20(11), 2522-2530.

Fair, D. A., Dosenbach, N. U., Church, J. A., Cohen, A. L., Brahmbhatt, S., Miezin, F. M., et al. (2007). Development of distinct control networks through segregation and integration. Proceedings of the National Academy of Sciences, 104(33), 13507-13512.

Filkowski, M. M., Olsen, R. M., Duda, B., Wanger, T. J., \& Sabatinelli, D. (2017). Sex differences in emotional perception: Meta-analysis of divergent activation. NeuroImage, 147, 925-933.

Fink, A., Benedek, M., Koschutnig, K., Pirker, E., Berger, E., Meister, S., et al. (2015). Training of verbal creativity modulates brain activity in regions associated with language-and memory-related demands. Human Brain Mapping, 36(10), 4104-4115.
Fjell, A. M., Walhovd, K. B., Fennema-Notestine, C., McEvoy, L. K., Hagler, D. J., Holland, D., et al. (2009). One-year brain atrophy evident in healthy aging. Journal of Neuroscience, 29(48), 1522315231.

Fox, M. D., Snyder, A. Z., Vincent, J. L., Corbetta, M., Van Essen, D. C., \& Raichle, M. E. (2005). The human brain is intrinsically organized into dynamic, anticorrelated functional networks. Proceedings of the National Academy of Sciences, 102(27), 9673-9678.

Frank, D. W., Dewitt, M., Hudgens-Haney, M., Schaeffer, D. J., Ball, B. H., Schwarz, N. F., et al. (2014). Emotion regulation: Quantitative meta-analysis of functional activation and deactivation. Neuroscience \& Biobehavioral Reviews, 45, 202-211.

Gaab, N., Gaser, C., \& Schlaug, G. (2006). Improvement-related functional plasticity following pitch memory training. NeuroImage, 31(1), 255-263.

Garavan, H., Kelley, D., Rosen, A., Rao, S. M., \& Stein, E. A. (2000). Practice-related functional activation changes in a working memory task. Microscopy Research and Technique, 51(1), 54-63.

Gates, N., \& Valenzuela, M. (2010). Cognitive exercise and its role in cognitive function in older adults. Current Psychiatry Reports, 12(1), 20-27.

Gates, N. J., Sachdev, P. S., Singh, M. A. F., \& Valenzuela, M. (2011). Cognitive and memory training in adults at risk of dementia: A systematic review. BMC Geriatrics, 11(1), 55 .

Geerligs, L., Maurits, N. M., Renken, R. J., \& Lorist, M. M. (2014). Reduced specificity of functional connectivity in the aging brain during task performance. Human Brain Mapping, 35(1), 319-330.

Goh, J. O. (2011). Functional dedifferentiation and altered connectivity in older adults: Neural accounts of cognitive aging. Aging and Disease, 2(1), 30.

Gold, B. T., Powell, D. K., Xuan, L., Jicha, G. A., \& Smith, C. D. (2010). Age-related slowing of task switching is associated with decreased integrity of frontoparietal white matter. Neurobiology of Aging, $31(3), 512-522$.

Grady, C. L. (2012). The cognitive neuroscience of ageing. Nature Reviews Neuroscience, 13(7), 491-505.

Hartwigsen, G., Baumgaertner, A., Price, C. J., Koehnke, M., Ulmer, S., \& Siebner, H. R. (2010). Phonological decisions require both the left and right supramarginal gyri. Proceedings of the National Academy of Sciences, 107(38), 16494-16499.

Haug, H., \& Eggers, R. (1991). Morphometry of the human cortex cerebri and corpus striatum during aging. Neurobiology of Aging, 12(4), 336-338.

Hedden, T., \& Gabrieli, J. D. (2004). Insights into the ageing mind: A view from cognitive neuroscience. Nature Reviews Neuroscience, 5(2), 87-96.

Heinzel, S., Schulte, S., Onken, J., Duong, Q. L., Riemer, T. G., Heinz, A., et al. (2014). Working memory training improvements and gains in non-trained cognitive tasks in young and older adults. Aging, Neuropsychology, and Cognition, 21(2), 146-173.

Heinzel, S., Metzger, F. G., Ehlis, A. C., Korell, R., Alboji, A., Haeussinger, F. B., et al. (2015). Age and vascular burden determinants of cortical hemodynamics underlying verbal fluency. PLoS One, 10(9), e0138863.

Heinzel, S., Lorenz, R. C., Pelz, P., Heinz, A., Walter, H., Kathmann, N., et al. (2016). Neural correlates of training and transfer effects in working memory in older adults. Neuroimage, 134, 236-249.

Hempel, A., Giesel, F. L., Garcia Caraballo, N. M., Amann, M., Meyer, H., Wüstenberg, T., et al. (2004). Plasticity of cortical activation related to working memory during training. American Journal of Psychiatry, 161(4), 745-747.

Hertzog, C., Kramer, A. F., Wilson, R. S., \& Lindenberger, U. (2009). Fit body, fit mind? Scientific American Mind, 20(4), 24-31. 
Hindin, S. B., \& Zelinski, E. M. (2012). Extended practice and aerobic exercise interventions benefit untrained cognitive outcomes in older adults: A meta-analysis. Journal of the American Geriatrics Society, 60(1), 136-141.

Hutchinson, J. B., Uncapher, M. R., \& Wagner, A. D. (2009). Posterior parietal cortex and episodic retrieval: Convergent and divergent effects of attention and memory. Learning \& Memory, 16(6), 343-356.

Hyodo, K., Dan, I., Suwabe, K., Kyutoku, Y., Yamada, Y., Akahori, M., et al. (2012). Acute moderate exercise enhances compensatory brain activation in older adults. Neurobiology of Aging, 33(11), 2621-2632.

Johansson, B. B. (2011). Current trends in stroke rehabilitation. A review with focus on brain plasticity. Acta Neurologica Scandinavica, 123(3), 147-159.

Jolles, D., \& Crone, E. A. (2012). Training the developing brain: A neurocognitive perspective. Frontiers in Human Neuroscience, 6, 76.

Jolles, D. D., van Buchem, M. A., Crone, E. A., \& Rombouts, S. A. (2013). Functional brain connectivity at rest changes after working memory training. Human Brain Mapping, 34(2), 396-406.

Karbach, J., \& Verhaeghen, P. (2014). Making working memory work: A meta-analysis of executive control and working memory training in older adults. Psychological Science, 25(11), 2027-2037.

Karnath, H. O., Ferber, S., \& Himmelbach, M. (2001). Spatial awareness is a function of the temporal not the posterior parietal lobe. Nature, 411(6840), 950-953.

Kelly, C., Foxe, J. J., \& Garavan, H. (2006). Patterns of normal human brain plasticity after practice and their implications for neurorehabilitation. Archives of Physical Medicine and Rehabilitation, 87(12), 20-29.

Kelly, M. E., Loughrey, D., Lawlor, B. A., Robertson, I. H., Walsh, C., \& Brennan, S. (2014). The impact of cognitive training and mental stimulation on cognitive and everyday functioning of healthy older adults: A systematic review and meta-analysis. Ageing Research Reviews, 15, 28-43.

Kerns, J. G., Cohen, J. D., MacDonald, A. W., Cho, R. Y., Stenger, V. A., \& Carter, C. S. (2004). Anterior cingulate conflict monitoring and adjustments in control. Science, 303(5660), 1023-1026.

Kirchhoff, B. A., Anderson, B. A., Barch, D. M., \& Jacoby, L. L. (2011). Cognitive and neural effects of semantic encoding strategy training in older adults. Cerebral Cortex, 22(4), 788-799.

Kirino, E., Belger, A., Goldman-Rakic, P., \& McCarthy, G. (2000). Prefrontal activation evoked by infrequent target and novel stimuli in a visual target detection task: an event-related functional magnetic resonance imaging study. Journal of Neuroscience, 20(17), 66126618.

Kray, J., \& Lindenberger, U. (2000). Adult age differences in task switching. Psychology and Aging, 15(1), 126.

Kray, J., Li, K. Z., \& Lindenberger, U. (2002). Age-related changes in task-switching components: The role of task uncertainty. Brain and Cognition, 49(3), 363-381.

Kueider, A. M., Parisi, J. M., Gross, A. L., \& Rebok, G. W. (2012). Computerized cognitive training with older adults: A systematic review. PLoS One, 7(7), e40588.

Laird, A. R., Fox, P. M., Price, C. J., Glahn, D. C., Uecker, A. M., Lancaster, J. L., et al. (2005). ALE meta-analysis: Controlling the false discovery rate and performing statistical contrasts. Human Brain Mapping, 25(1), 155-164.

Lampit, A., Hallock, H., \& Valenzuela, M. (2014). Computerized cognitive training in cognitively healthy older adults: A systematic review and meta-analysis of effect modifiers. PLoS Medicine, 11(11), e1001756.

Langenecker, S. A., Nielson, K. A., \& Rao, S. M. (2004). fMRI of healthy older adults during Stroop interference. NeuroImage, 21(1), 192200.
Li, K. Z., \& Lindenberger, U. (2002). Relations between aging sensory/ sensorimotor and cognitive functions. Neuroscience \& Biobehavioral Reviews, 26(7), 777-783.

Li, R., Zhu, X., Yin, S., Niu, Y., Zheng, Z., Huang, X., et al. (2014). Multimodal intervention in older adults improves resting-state functional connectivity between the medial prefrontal cortex and medial temporal lobe. Frontiers in Aging Neuroscience, 6, 39.

Li, T., Yao, Y., Cheng, Y., Xu, B., Cao, X., Waxman, D., et al. (2016). Cognitive training can reduce the rate of cognitive aging: A neuroimaging cohort study. BMC Geriatrics, 16(1), 12.

Lindbergh, C. A., Dishman, R. K., \& Miller, L. S. (2016). Functional disability in mild cognitive impairment: A systematic review and meta-analysis. Neuropsychology Review, 26(2), 129-159.

Liu-Ambrose, T., Nagamatsu, L. S., Voss, M. W., Khan, K. M., \& Handy, T. C. (2012). Resistance training and functional plasticity of the aging brain: A 12-month randomized controlled trial. Neurobiology of Aging, 33(8), 1690-1698.

Loewenstein, D. A., Acevedo, A., Czaja, S. J., \& Duara, R. (2004). Cognitive rehabilitation of mildly impaired Alzheimer disease patients on cholinesterase inhibitors. The American Journal of Geriatric Psychiatry, 12(4), 395-402.

Luo, C., Zhang, X., Cao, X., Gan, Y., Li, T., Cheng, Y., et al. (2016). The lateralization of intrinsic networks in the aging brain implicates the effects of cognitive training. Frontiers in Aging Neuroscience, 8, 32 .

Lustig, C., Shah, P., Seidler, R., \& Reuter-Lorenz, P. A. (2009). Aging, training, and the brain: A review and future directions. Neuropsychology Review, 19(4), 504-522.

Madden, D. J. (1990). Adult age differences in the time course of visual attention. Journal of Gerontology, 45(1), P9-P16.

Madden, D. J., Costello, M. C., Dennis, N. A., Davis, S. W., Shepler, A. M., Spaniol, J., et al. (2010). Adult age differences in functional connectivity during executive control. NeuroImage, 52(2), 643-657.

Maguire, E. A., Spiers, H. J., Good, C. D., Hartley, T., Frackowiak, R. S., \& Burgess, N. (2003). Navigation expertise and the human hippocampus: A structural brain imaging analysis. Hippocampus, 13(2), $250-259$.

Mahncke, H. W., Connor, B. B., Appelman, J., Ahsanuddin, O. N., Hardy, J. L., Wood, R. A., et al. (2006). Memory enhancement in healthy older adults using a brain -based training program: A randomized, controlled study. Proceedings of the National Academy of Sciences, 103(33), 12523-12528.

Mason, M. F., Norton, M. I., Van Horn, J. D., Wegner, D. M., Grafton, S. T., \& Macrae, C. N. (2007). Wandering minds: The default network and stimulus-independent thought. Science, 315(5810), 393-395.

Mattay, V. S., Fera, F., Tessitore, M. D., Hariri, A. R., Das, S., Callicott, J. H., et al. (2002). Neurophysiological correlates of age-related changes in human motor function. Neurology, 58(4), 630-635.

May, A. (2011). Experience-dependent structural plasticity in the adult human brain. Trends in Cognitive Sciences, 15(10), 475-482.

McDaniel, M. A., Binder, E. F., Bugg, J. M., Waldum, E. R., Dufault, C., Meyer, A., et al. (2014). Effects of cognitive training with and without aerobic exercise on cognitively-demanding everyday activities. Psychology and Aging, 29(3), 717-730.

McDonough, I. M., Haber, S., Bischof, G. N., \& Park, D. C. (2015). The Synapse Project: Engagement in mentally challenging activities enhances neural efficiency. Restorative Neurology and Neuroscience, 33(6), 865-882.

Mewborn, C. M., Lindbergh, C. A., \& Miller, L. S. (2017). Cognitive interventions for cognitively healthy, mildly impaired, and mixed samples of older adults: a systematic review and meta-analysis of randomized-controlled trials. Neuropsychology Review, 27(4), 403439. 
Moher, D., Liberati, A., Tetzlaff, J., Altman, D. G., \& Prisma Group. (2009). Preferred reporting items for systematic reviews and metaanalyses: The PRISMA statement. PLoS Medicine, 6(7), e1000097.

Morcom, A. M., \& Johnson, W. (2015). Neural reorganization and compensation in aging. Journal of Cognitive Neuroscience, 27(7), 1275-1285.

Motes, M. A., Yezhuvath, U. S., Aslan, S., Spence, J. S., Rypma, B., \& Chapman, S. B. (2018). Higher-order cognitive training effects on processing speed-related neural activity: A randomized trial. Neurobiology of Aging, 62, 72-81.

Mozolic, J. L., Hayaska, S., \& Laurienti, P. J. (2010). A cognitive training intervention increases resting cerebral blood flow in healthy older adults. Frontiers in Human Neuroscience, 4, 16.

Murphy, S. E., O’Donoghue, M. C., Blackwell, S. E., Nobre, A. C., Browning, M., \& Holmes, E. A. (2017). Increased rostral anterior cingulate activity following positive mental imagery training in healthy older adults. Social Cognitive and Affective Neuroscience, 12(12), 1950-1958.

Nagahama, Y., Fukuyama, H., Yamauchi, H., Matsuzaki, S., Konishi, J., Shibasaki, H., \& Kimura, J. (1996). Cerebral activation during performance of a card sorting test. Brain, 119(5), 1667-1676.

Nagahama, Y., Okada, T., Katsumi, Y., Hayashi, T., Yamauchi, H., Sawamoto, N., et al. (1999). Transient neural activity in the medial superior frontal gyrus and precuneus time locked with attention shift between object features. NeuroImage, 10(2), 193-199.

Nagamatsu, L. S., Handy, T. C., Hsu, C. L., Voss, M., \& Liu-Ambrose, T. (2012). Resistance training promotes cognitive and functional brain plasticity in seniors with probable mild cognitive impairment. Archives of Internal Medicine, 172(8), 666-668.

National Institute on Aging, \& World Health Organization (2011). Global Health and Aging. Retrieved from http://www.nia.nih.gov/research/ publication/global-health-and-aging/humanity's-aging.

Nee, D. E., Jahn, A., \& Brown, J. W. (2014). Prefrontal cortex organization: Dissociating effects of temporal abstraction, relational abstraction, and integration with fMRI. Cerebral Cortex, 24(9), $2377-$ 2387.

Neely, A. S., Vikström, S., \& Josephsson, S. (2009). Collaborative memory intervention in dementia: Caregiver participation matters. Neuropsychological Rehabilitation, 19(5), 696-715.

Niendam, T. A., Laird, A. R., Ray, K. L., Dean, Y. M., Glahn, D. C., \& Carter, C. S. (2012). Meta-analytic evidence for a superordinate cognitive control network subserving diverse executive functions. Cognitive, Affective, \& Behavioral Neuroscience, 12(2), 241-268.

Noack, H., Lövdén, M., \& Schmiedek, F. (2014). On the validity and generality of transfer effects in cognitive training research. Psychological Research, 78(6), 773-789.

Nudo, R. (2003). Adaptive plasticity in motor cortex: Implications for rehabilitation after brain injury. Journal of Rehabilitation MedicineSupplements, 41, 7-10.

Nyberg, L., Sandblom, J., Jones, S., Neely, A. S., Petersson, K. M., Ingvar, M., \& Bäckman, L. (2003). Neural correlates of trainingrelated memory improvement in adulthood and aging. Proceedings of the National Academy of Sciences, 100(23), 13728-13733.

Nyberg, L., Dahlin, E., Neely, A., \& Bäckman, L. (2009). Neural correlates of variable working memory load across adult age and skill: Dissociative patterns within the fronto-parietal network. Scandinavian Journal of Psychology, 50(1), 41-46.

Nyberg, L., Lövdén, M., Riklund, K., Lindenberger, U., \& Bäckman, L. (2012). Memory aging and brain maintenance. Trends in Cognitive Sciences, 16(5), 292-305.

Olesen, P. J., Westerberg, H., \& Klingberg, T. (2004). Increased prefrontal and parietal activity after training of working memory. Nature Neuroscience, 7(1), 75-79.
Osaka, M., Otsuka, Y., \& Osaka, N. (2012). Verbal to visual code switching improves working memory in older adults: An fMRI study. Frontiers in Human Neuroscience, 6, 24.

Oswald, W. D., Gunzelmann, T., Rupprecht, R., \& Hagen, B. (2006). Differential effects of single versus combined cognitive and physical training with older adults: The SimA study in a 5-year perspective. European Journal of Ageing, 3(4), 179-192.

Outhred, T., Hawkshead, B. E., Wager, T. D., Das, P., Malhi, G. S., \& Kemp, A. H. (2013). Acute neural effects of selective serotonin reuptake inhibitors versus noradrenaline reuptake inhibitors on emotion processing: Implications for differential treatment efficacy. Neuroscience \& Biobehavioral Reviews, 37(8), 1786-1800.

Owen, A. M., Hampshire, A., Grahn, J. A., Stenton, R., Dajani, S., Burns, A. S., et al. (2010). Putting brain training to the test. Nature, 465(7299), 775.

Parker, S., Jagger, C., Lamura, G., Chiatti, C., Wahl, H., Iwarsson, S., ... \& Walker, A. (2012). FUTURAGE: Creating a road map for ageing research. European Geriatric Medicine, 3, S100-S101.

Pacheco, J., Goh, J. O., Kraut, M. A., Ferrucci, L., \& Resnick, S. M. (2015). Greater cortical thinning in normal older adults predicts later cognitive impairment. Neurobiology of Aging, 36(2), 903-908.

Papp, K. V., Walsh, S. J., \& Snyder, P. J. (2009). Immediate and delayed effects of cognitive interventions in healthy elderly: A review of current literature and future directions. Alzheimer's \& Dementia, $5(1), 50-60$.

Patel, R., Spreng, R. N., \& Turner, G. R. (2013). Functional brain changes following cognitive and motor skills training: A quantitative metaanalysis. Neurorehabilitation and Neural Repair, 27(3), 187-199.

Peretz, C., Korczyn, A. D., Shatil, E., Aharonson, V., Birnboim, S., \& Giladi, N. (2011). Computer-based, personalized cognitive training versus classical computer games: A randomized double-blind prospective trial of cognitive stimulation. Neuroepidemiology, 36(2), 91-99.

Persson, J., Nyberg, L., Lind, J., Larsson, A., Nilsson, L. G., Ingvar, M., \& Buckner, R. L. (2006). Structure-function correlates of cognitive decline in aging. Cerebral Cortex, 16(7), 907-915.

Persson, J., Lustig, C., Nelson, J. K., \& Reuter-Lorenz, P. A. (2007). Age differences in deactivation: A link to cognitive control? Journal of Cognitive Neuroscience, 19(6), 1021-1032.

Price, C. J. (2010). The anatomy of language: A review of $100 \mathrm{fMRI}$ studies published in 2009. Annals of the New York Academy of Sciences, 1191(1), 62-88.

Prince, M., Bryce, R., Albanese, E., Wimo, A., Ribeiro, W., \& Ferri, C. P. (2013). The global prevalence of dementia: A systematic review and meta-analysis. Alzheimer's \& Dementia, 9(1), 63-75.

Qiu, F. T., \& Von Der Heydt, R. (2005). Figure and ground in the visual cortex: V2 combines stereoscopic cues with gestalt rules. Neuron, 47(1), 155-166.

Quayhagen, M. P., Quayhagen, M., Corbeil, R. R., Hendrix, R. C., Jackson, J. E., Snyder, L., \& Bower, D. (2000). Coping with dementia: Evaluation of four nonpharmacologic interventions. International Psychogeriatrics, 12(2), 249-265.

Ranganath, C., \& Rainer, G. (2003). Cognitive neuroscience: Neural mechanisms for detecting and remembering novel events. Nature Reviews Neuroscience, 4(3), 193-202.

Raz, N., Lindenberger, U., Rodrigue, K. M., Kennedy, K. M., Head, D., Williamson, A., et al. (2005). Regional brain changes in aging healthy adults: General trends, individual differences and modifiers. Cerebral Cortex, 15(11), 1676-1689.

Rebok, G. W., Carlson, M. C., \& Langbaum, J. B. (2007). Training and maintaining memory abilities in healthy older adults: Traditional and novel approaches. The Journals of Gerontology Series B: Psychological Sciences and Social Sciences, 62(1), 53-61. 
Reuter-Lorenz, P. A., \& Park, D. C. (2014). How does it STAC up? Revisiting the scaffolding theory of aging and cognition. Neuropsychology Review, 24(3), 355-370.

Reuter-Lorenz, P. A., Jonides, J., Smith, E. E., Hartley, A., Miller, A., Marshuetz, C., \& Koeppe, R. A. (2000). Age differences in the frontal lateralization of verbal and spatial working memory revealed by PET. Journal of Cognitive Neuroscience, 12(1), 174-187.

Rosano, C., Venkatraman, V. K., Guralnik, J., Newman, A. B., Glynn, N. W., Launer, L., Aizenstein, H. (2010). Psychomotor speed and functional brain MRI 2 years after completing a physical activity treatment. Journals of Gerontology Series A: Biomedical Sciences and Medical Sciences, 65(6), 639-647.

Roy, S., Ficarro, S., Duberstein, P., Chapman, B. P., Dubovsky, S., Paroski, M., et al. (2016). Executive function and personality predict instrumental activities of daily living in Alzheimer disease. The American Journal of Geriatric Psychiatry, 24(11), 1074-1083.

Ruffieux, J., Mouthon, A., Keller, M., Mouthon, M., Annoni, J. M., \& Taube, W. (2018). Balance training reduces brain activity during motor simulation of a challenging balance task in older adults: An fMRI study. Frontiers in Behavioral Neuroscience, 12, 10.

Ruscheweyh, R., Deppe, M., Lohmann, H., Wersching, H., Korsukewitz, C., Duning, T., et al. (2013). Executive performance is related to regional gray matter volume in healthy older individuals. Human Brain Mapping, 34(12), 3333-3346.

Rypma, B., Prabhakaran, V., Desmond, J. E., Glover, G. H., \& Gabrieli, J. D. (1999). Load-dependent roles of frontal brain regions in the maintenance of working memory. NeuroImage, 9(2), 216-226.

Sabatinelli, D., Fortune, E. E., Li, Q., Siddiqui, A., Krafft, C., Oliver, W. T., et al. (2011). Emotional perception: Meta-analyses of face and natural scene processing. NeuroImage, 54(3), 2524-2533.

Salat, D. H., Buckner, R. L., Snyder, A. Z., Greve, D. N., Desikan, R. S., Busa, E., et al. (2004). Thinning of the cerebral cortex in aging. Cerebral Cortex, 14(7), 721-730.

Salthouse, T. A. (1996). The processing-speed theory of adult age differences in cognition. Psychological Review, 103(3), 403.

Sayala, S., Sala, J. B., \& Courtney, S. M. (2006). Increased neural efficiency with repeated performance of a working memory task is information-type dependent. Cerebral Cortex, 16(5), 609-617.

Schmitter-Edgecombe, M., Parsey, C., \& Cook, D. J. (2011). Cognitive correlates of functional performance in older adults: Comparison of self-report, direct observation, and performance-based measures. Journal of the International Neuropsychological Society, 17(5), 853-864.

Schneiders, J. A., Opitz, B., Krick, C. M., \& Mecklinger, A. (2011). Separating intra-modal and across-modal training effects in visual working memory: An fMRI investigation. Cerebral Cortex, 21(11), 2555-2564.

Shah, T. M., Weinborn, M., Verdile, G., Sohrabi, H. R., \& Martins, R. N. (2017). Enhancing cognitive functioning in healthly older adults: A systematic review of the clinical significance of commercially available computerized cognitive training in preventing cognitive decline. Neuropsychology Review, 27(1), 62-80.

Silsupadol, P., Shumway-Cook, A., Lugade, V., van Donkelaar, P., Chou, L. S., Mayr, U., \& Woollacott, M. H. (2009). Effects of single-task versus dual-task training on balance performance in older adults: A double-blind, randomized controlled trial. Archives of Physical Medicine and Rehabilitation, 90(3), 381-387.

Smith, A. R., Smith, R. G., Condliffe, D., Hannon, E., Schalkwyk, L., Mill, J., \& Lunnon, K. (2016). Increased DNA methylation near TREM2 is consistently seen in the superior temporal gyrus in Alzheimer's disease brain. Neurobiology of Aging, 47, 35-40.

Sohn, M. H., Ursu, S., Anderson, J. R., Stenger, V. A., \& Carter, C. S. (2000). The role of prefrontal cortex and posterior parietal cortex in task switching. Proceedings of the National Academy of Sciences, 97(24), 13448-13453.

Solbakk, A. K., Alpert, G. F., Furst, A. J., Hale, L. A., Oga, T., Chetty, S., et al. (2008). Altered prefrontal function with aging: Insights into age-associated performance decline. Brain Research, 1232, 30- 47.

Spreng, R. N., \& Schacter, D. L. (2012). Default network modulation and large-scale network interactivity in healthy young and old adults. Cerebral Cortex, 22(11), 2610-2621.

Suchy, Y., Kraybill, M. L., \& Franchow, E. (2011). Instrumental activities of daily living among community-dwelling older adults: Discrepancies between self-report and performance are mediated by cognitive reserve. Journal of Clinical and Experimental Neuropsychology, 33(1), 92-100.

Tomasi, D., Ernst, T., Caparelli, E. C., \& Chang, L. (2006). Common deactivation patterns during working memory and visual attention tasks: An intra-subject fMRI study at 4 tesla. Human Brain Mapping, 27(8), 694-705.

Turkeltaub, P. E., Eden, G. F., Jones, K. M., \& Zeffiro, T. A. (2002). Meta-analysis of the functional neuroanatomy of single-word reading: Method and validation. NeuroImage, 16(3), 765-780.

Uddin, L. Q., Clare Kelly, A. M., Biswal, B. B., Xavier Castellanos, F., \& Milham, M. P. (2009). Functional connectivity of default mode network components: Correlation, anticorrelation, and causality. Human Brain Mapping, 30(2), 625-637.

Valenzuela, M. J., Jones, M., Rae, W. W. C., Graham, S., Shnier, R., \& Sachdev, P. (2003). Memory training alters hippocampal neurochemistry in healthy elderly. Neuroreport, 14(10), 1333-1337.

Vincent, J. L., Kahn, I., Snyder, A. Z., Raichle, M. E., \& Buckner, R. L. (2008). Evidence for a frontoparietal control system revealed by intrinsic functional connectivity. Journal of Neurophysiology, 100(6), 3328-3342.

von der Heydt, R., Peterhans, E., \& Baumgartner, G. (1984). Illusory contours and cortical neuron responses. Science, 224, 1260-1262.

Voss, M. W., Prakash, R. S., Erickson, K. I., Basak, C., Chaddock, L., Kim, J. S., et al. (2010). Plasticity of brain networks in a randomized intervention trial of exercise training in older adults. Frontiers in Aging Neuroscience, 2, 32.

West, R. L., Welch, D. C., \& Yassuda, M. S. (2000). Innovative approaches to memory training for older adults. Cognitive Rehabilitation in Old Age, 81-105.

Wegbreit, E., Cushman, G. K., Puzia, M. E., Weissman, A. B., Kim, K. L., Laird, A. R., \& Dickstein, D. P. (2014). Developmental metaanalyses of the functional neural correlates of bipolar disorder. JAMA Psychiatry, 71(8), 926-935.

Willis, S. L., Tennstedt, S. L., Marsiske, M., Ball, K., Elias, J., Koepke, K. M., et al. (2006). Long-term effects of cognitive training on everyday functional outcomes in older adults. JAMA, 296(23), 28052814.

Wood, K. N., Nikolov, R., \& Shoemaker, J. K. (2016). Impact of longterm endurance training vs. guideline-based physical activity on brain structure in healthy aging. Frontiers in Aging Neuroscience, $8,155$.

Wortmann, M. (2012). Dementia: A global health priority-highlights from an ADI and World Health Organization report. Alzheimer's Research \& Therapy, 4(5), 40.

Wu, J. T., Wu, H. Z., Yan, C. G., Chen, W. X., Zhang, H. Y., He, Y., \& Yang, H. S. (2011). Aging-related changes in the default mode network and its anti-correlated networks: A resting-state fMRI study. Neuroscience Letters, 504(1), 62-67.

Yamaguchi, S., Hale, L. A., D'esposito, M., \& Knight, R. T. (2004). Rapid prefrontal-hippocampal habituation to novel events. Journal of Neuroscience, 24(23), 5356-5363. 
Yeo, B. T., Krienen, F. M., Eickhoff, S. B., Yaakub, S. N., Fox, P. T., Buckner, R. L., et al. (2014). Functional specialization and flexibility in human association cortex. Cerebral Cortex, 25(10), 3654 3672.

Yin, S., Zhu, X., Li, R., Niu, Y., Wang, B., Zheng, Z., et al. (2014). Intervention-induced enhancement in intrinsic brain activity in healthy older adults. Scientific Reports, 4, 7309.

Zacks, R. T., Hasher, L., \& Li, K. Z. H. (2000). Human memory. In F. I. M. Craik \& T. A. Salthouse (Eds.), The handbook of aging and cognition (pp. 293-357). Mahwah: Lawrence Erlbaum Associates Publishers.
Zanto, T. P., \& Gazzaley, A. (2013). Fronto-parietal network: Flexible hub of cognitive control. Trends in Cognitive Sciences, 17(12), 602-603.

Zinke, K., Zeintl, M., Rose, N. S., Putzmann, J., Pydde, A., \& Kliegel, M. (2014). Working memory training and transfer in older adults: Effects of age, baseline performance, and training gains. Developmental Psychology, 50(1), 304.

Publisher's note Springer Nature remains neutral with regard to jurisdictional claims in published maps and institutional affiliations. 